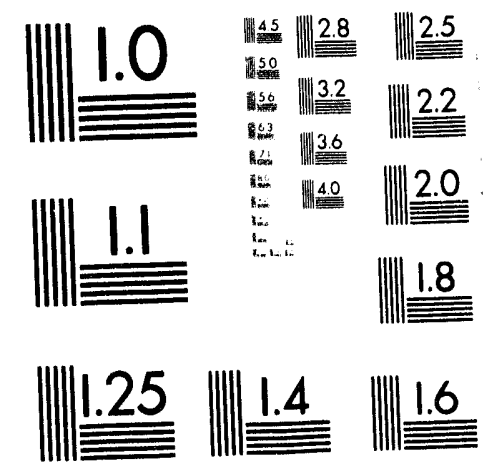



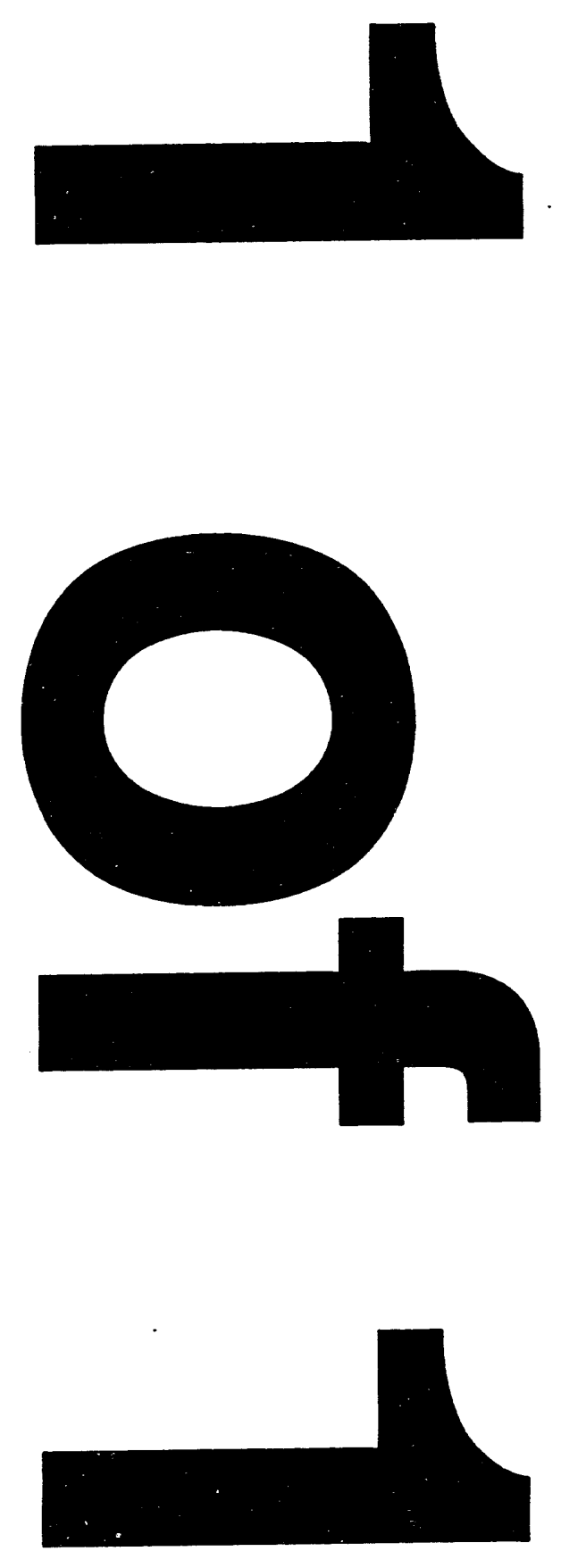


\section{THE GKOWTंH OF InAsSb/InGaAs STRAINED-LAYER SUPERLATTICES BY METAL-ORGANIC CHEMICAL VAPOR DEPOSITION}

R. M. Biefeld, K. C. Baucom, S. R. Kurtz, and D. M. Follstaedt

Sandia National Laboratory, Albuquerque, NM

$$
\text { Conf }-931108-48
$$

\section{ABSTRACT}

We have grown InAs 1-x $\mathrm{Sb}_{\mathrm{x}} / \mathrm{In}_{1-\mathrm{y}} \mathrm{Ga}_{y} \mathrm{As}$ strained-layer superlattice (SLS) semiconductors lattice matched to InAs using a variety of conditions by metal-organic chemical vapor deposition. The V/III ratio was varied from 2.5 to 10 at a temperature of $475{ }^{\circ} \mathrm{C}$, at pressures of 200 to 660 torr and growth rates of $3-5 \AA / \mathrm{s}$ and layer thicknesses ranging from 55 to $152 \AA$. The composition of the InAsSb ternary can be predicted from the input gas molar flow rates using a thermodynamic model. At lower temperatures, the thermodynamic model must be modified to take account of the incomplete decomposition of arsine and trimethylantimony. Diodes have been prepared using $\mathrm{Zn}$ as the p-type dopant and undoped SLS as the n-type material. The diode was found to emit at $3.56 \mu \mathrm{m}$. These layers have been characterized by optical microscopy, SIMS, x-ray diffraction, and transmission electron diffraction. The optical properties of these SLS's were determined by infrared photoluminescence and absorption measurements.

\section{INTRODUCTION}

The growth of InAs $1-\mathrm{x} \mathrm{Sb}_{\mathrm{x}} / \mathrm{In}_{1-\mathrm{y}} \mathrm{Gay}_{\mathrm{y}} \mathrm{As}$ SLS's is being explored by us for their possible use in mid-wave, $2-5 \mu \mathrm{m}$ infrared optoelectronic and heterojunction devices. This system was chosen because the compositions span the $2-5 \mu \mathrm{m}$ wavelength range and they can be grown lattice matched to InAs. Recent results by Menna et al. on a metal-organic chemical vapor deposition (MOCVD) grown $3.06 \mu \mathrm{m}$ diode laser with a maximum operating temperature of 35 $\mathrm{K}$ and threshold current densities of $200-330 \mathrm{~A} / \mathrm{cm}^{2}$ indicate the potential and the need for devices operating in this wavelength range. ${ }^{1}$ Our previous studies in the Sb rich end of the InAsSb ternary system have demonstrated accurate composition control through the use of a thermodynamic model and high quality infrared detectors have been made in our laboratory from doped strained-layer superlattices (SLS's) grown by MOCVD in the Sb rich end of this ternary. 2,3

The initial studies reported on here focused on the growth of InAs 1-x $\mathrm{Sb}_{\mathrm{x}} / \mathrm{In}_{1-y} \mathrm{Ga}_{y} \mathrm{As}$ heterostructures on InAs. The studies concentrated on the growth and characterization of the InAsSb layers due to the importance of this material in the active devices. The thermodynamic model used to describe composition control in the $\mathrm{Sb}$ rich compositions can also be used to predict the composition of As rich materials. The details of the growth conditions for InAs1${ }_{x} S_{x} / \operatorname{In} 1-y G_{y} A s$ SLS's and InAs $1-x b_{x}$ alloys, and the growth and characterization of an infrared photodiode and the applicability to infrared devices of As rich InAs 1-x Sb $b_{x}$ materials are also discussed.

\section{EXPERIMENTAL}

This investigation was carried out in a previously described horizontal MOCVD system. ${ }^{4}$ The sources of In, Sb and As were trimethylindium (TMIn), trimethylantimony (TMSb), trimethylgallium (TMG), and 100 percent arsine $\left(\mathrm{AsH}_{3}\right)$, respectively. Hydrogen was used as the carrier gas at a total flow of 6 SLM. The III/V ratio was varied from 2.7 to 10.3 over a temperature range of $475-525^{\circ} \mathrm{C}$, at total growth pressures of 200 to 660 torr and growth rates of 0.75 to $3.0 \mu \mathrm{m} / \mathrm{h}$. The growth was performed on (001) InAs substrates. Diodes have been

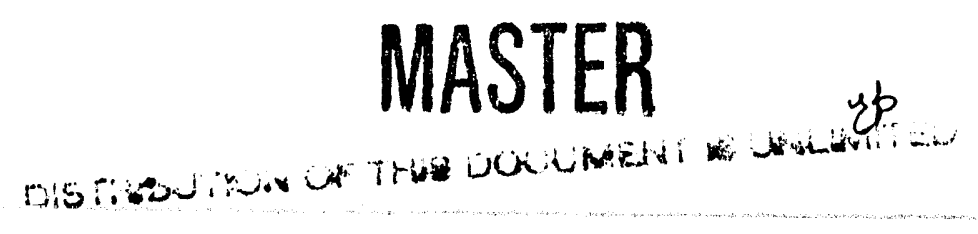


prepared using $\mathrm{Zn}$ as the p-type dopant with diethylzinc as the precursor and undoped SLS as the n-type material. InAs was cleaned by degreasing in solvents and deionized water. It was then etched for one minute in a 10:1 mixture of sulfuric acid and hydrogen peroxide, rinsed with deionized water and blown dry with nitrogen.

$\mathrm{Sb}$ compositions, $\mathrm{x}$, reported for the $\operatorname{InAs} 1-\mathrm{x} \mathrm{Sb}_{\mathrm{x}}$ layers were determined by $\mathrm{x}$-ray diffraction using a $\mathrm{Cu} x$-ray source and a four crystal Si monochromator. The $(004)$ reflection was used to measure the lattice constant normal to the growth plane and the (115) or (335) reflections were used to determine the in-plane latrice constant. ${ }^{4}$ In this way the composition determination is corrected for partial strain relaxation by misfit dislocations. Some samples were also checked for impurities using secondary ion mass spectroscopy (SIMS).

Infrared photoluminescence was measured at $14 \mathrm{~K}$ using a double-modulation technique which provides high sensitivity, reduces sample heating, and eliminates the blackbody background from infrared emission spectra. ${ }^{5}$ The absorption measurements were carried out on polished samples using a Fourier transform infrared spectrometer.

Cross-sectional specimens of some samples were prepared by cleaving along (110) and epoxying two alloy surfaces together. A cylinder centered on the epoxied interface was ultrasonically cored and epoxied into a brass tube for mechanical strength. Disks were sliced from the tube and were mechanically thinned at their centers with a rotating wheel "dimpler" using $1 \mu \mathrm{m}$ diamond paste. Final thinning was done by ion milling with Ar, followed by a short milling time in $I_{2}$ vapor to remove In residue on the surface. Transmission electron microscopy (TEM) examination was done using a Philips CM20T (200 keV) microscope. The specimens were examined in a $<110>$ direction perpendicular to the [001] growth direction. Both transmission electron diffraction (TED) patterns and TEM images were obtained. Surface optical photomicrographs were obtained with a Zeiss Ultraphot microscope equipped with Nomarski interference contrast objectives.

\section{RESULTS AND DISCUSSION}

The growth of InAs 1-x $\mathrm{Sb}_{\mathrm{x}} / \mathrm{In}_{1-\mathrm{yGa}} \mathrm{As}$ SLS's was investigated using III/V ratios between 2.7 and 10.3 at a temperature of $475^{\circ} \mathrm{C}$, at total growth pressures of 200 to 660 torr and growth rates of $1-1.8 \mu \mathrm{m} / \mathrm{h}$. The group $\mathrm{V}$ molar fraction of TMSb in the vapor phase [nTMSb/(nTMSb $+\mathrm{n}_{\mathrm{AsH}}$ )] was varied from 0.06 to 0.09 . The growth results for the As rich end of the InAs $1-\mathrm{x} \mathrm{Sb}_{\mathrm{x}}$ ternary are similar to those described previously for the $\mathrm{Sb}$ rich end of the ternary. ${ }^{6}$ The growth rate was found to be proportional to the TMIn and the TMGa flow into the reaction chamber and independent of the TMSb and $\mathrm{AsH}_{3}$ flow.

The observed trends for the effects of input vapor concentrations on the resulting solid composition can be completely described by a thermodynamic model. ${ }^{6}$ The model predicts that the thermodynamically more stable III/V compound will control the composition. For the InAsSb system when III/ $<<1$, As is preferentially incorporated into the solid and the solidvapor distribution coefficient of $\mathrm{Sb}(\mathrm{kSb})$ is $<1$. This is because InAs is more stable, has a lower free energy of formation, than InSb at $475-525^{\circ} \mathrm{C}$. For III/V ratios close to one, $k \mathrm{Sb}$ approaches one and for III/V $\geq 1, k \mathrm{Sb}=1$. When III/V $\geq 1$, all of the group V materials, As and $\mathrm{Sb}$, will be incorporated into the solid at their vapor concentrations. These trends are also found for this data for As rich InAsSb. However, some slight deviations from the predicied behavior of the thermodynamic model are observed for the present results. For some of the samples grown at $475{ }^{\circ} \mathrm{C}, k \mathrm{Sb}$ appears to be $\geq 1$. This can be explained by assuming that not all of the $\mathrm{AsH}_{3}$ is decomposed at this temperature. This assumption is consistent with the reported incomplete decomposition of $\mathrm{AsH}_{3}$ at temperatures below $500{ }^{\circ} \mathrm{C} .7$

An x-ray diffraction pattern of a selected InAs 1-x $\mathrm{Sb}_{\mathrm{x}} / \mathrm{In}_{1-\mathrm{yGa}} \mathrm{As}$ SLS is shown in Figure 1. The pattern shown is for sample CVD1242 which was also fabricated into a light emitting diode (LED) structure. The calculated pattern is for an $\operatorname{InAs} 0.91 \mathrm{Sb}_{0.09} / \mathrm{In}_{0.94} \mathrm{Ga}_{0.06} \mathrm{As}$ SLS with $110 \AA / 116 \AA$ layer thicknesses. The slight asymmetry and line widths of the peaks 


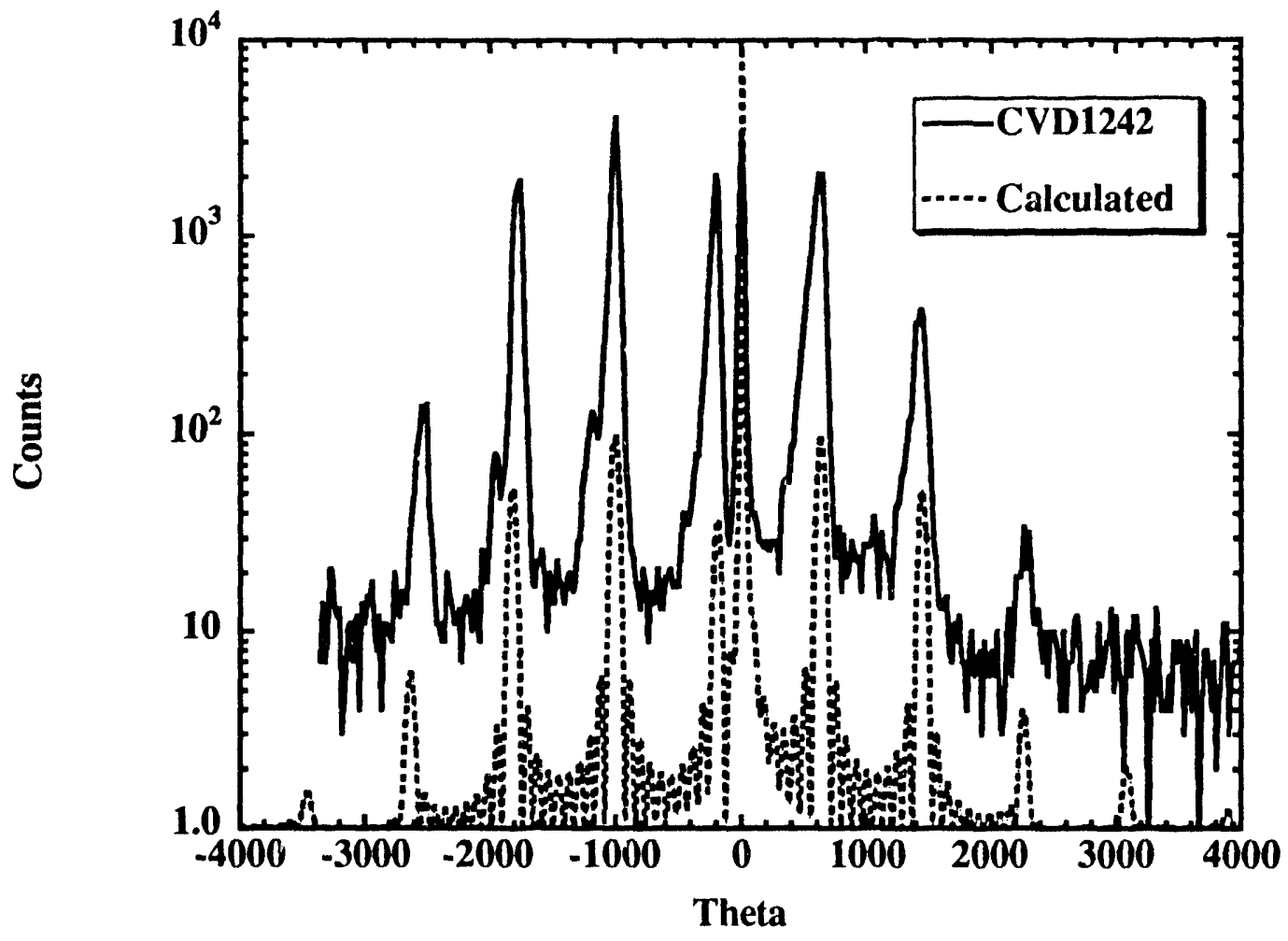

Figure 1. The $x$-ray diffraction pattern of CVD1242 indicates a lattice mismatch with InAs equal to -200 arc seconds which corresponds to a $\Delta \mathrm{a} / \mathrm{a}_{0}$ of $1.6 \times 10^{-3}$.

can be explained by assuming either that there are some dislocations in the structure or that a layer of In 1-x GaxAs1-ySby occurs at interfaces in the SLS.

The bandgap of the unstrained, InAs $0.9 \mathrm{Sb}_{0.1}$ alloy was determined to be approximately $270 \mathrm{meV}$ from optical studies of bulk ternary alloy and subsequent studies of SLSs and quantum wells. The accepted value for InAs $0.9 \mathrm{Sb}_{0.1}$ is $\approx 330 \mathrm{meV} .8$ Throughout our studies of As-rich, InAsSb $(5-50 \% \mathrm{Sb})$, the optically determined bandgap of InAsSb alloys was smaller than accepted values. ${ }^{8}$ This InAsSb bandgap anomaly was observed in both MOCVD and MBE grown samples. Electron diffraction results indicate that compositional ordering is occurring in InAs ${ }_{0.86} \mathrm{Sb}_{0.14}$. The type of ordering which occurs is the same as that which was previously observed for InAs0.6 $\mathrm{Sb0.4}$ and is on the $\{111\}$ planes of the group-V sublattice (CuPt-type). ${ }^{9}$ Compositional ordering of InAsSb should result in bandgap reduction.9,10 Details about ordering and the optical characterization of these SLSs will be discussed in a later publication.

Initial attempts to dope these SLSs produced infrared LEDs. The LED consisted of $1 \mu \mathrm{m}$ of p-type SLS $\left(\mathrm{Zn} \approx 5 \times 10^{18} \mathrm{~cm}^{-3}\right)$ grown on $2 \mu \mathrm{m}$ of undoped SLS (n-type background doping) on an n-type InAs substrate. The structure of the SLS determined by $\mathrm{x}$-ray analysis was In $\mathrm{As}_{0.91} \mathrm{Sb}_{0.09} / \mathrm{In}_{0.94} \mathrm{Ga}_{0.06} \mathrm{As}$ ( $110 \AA / 116 \AA$ layer thicknesses). The LEDs were fabricated into unpassivated, mesa structures. The forward-bias LED emission, photoluminescence spectrum, and photovoltaic spectral responsivity (all at 77K) for the LED are shown in Figure 2. All spectra were obtained with an FTIR spectrometer equipped with an InSb detector. A $\mathrm{Nd}$ :YAG laser $(1.06 \mu \mathrm{m})$ was used for excitation in the photoluminescence experiment. 


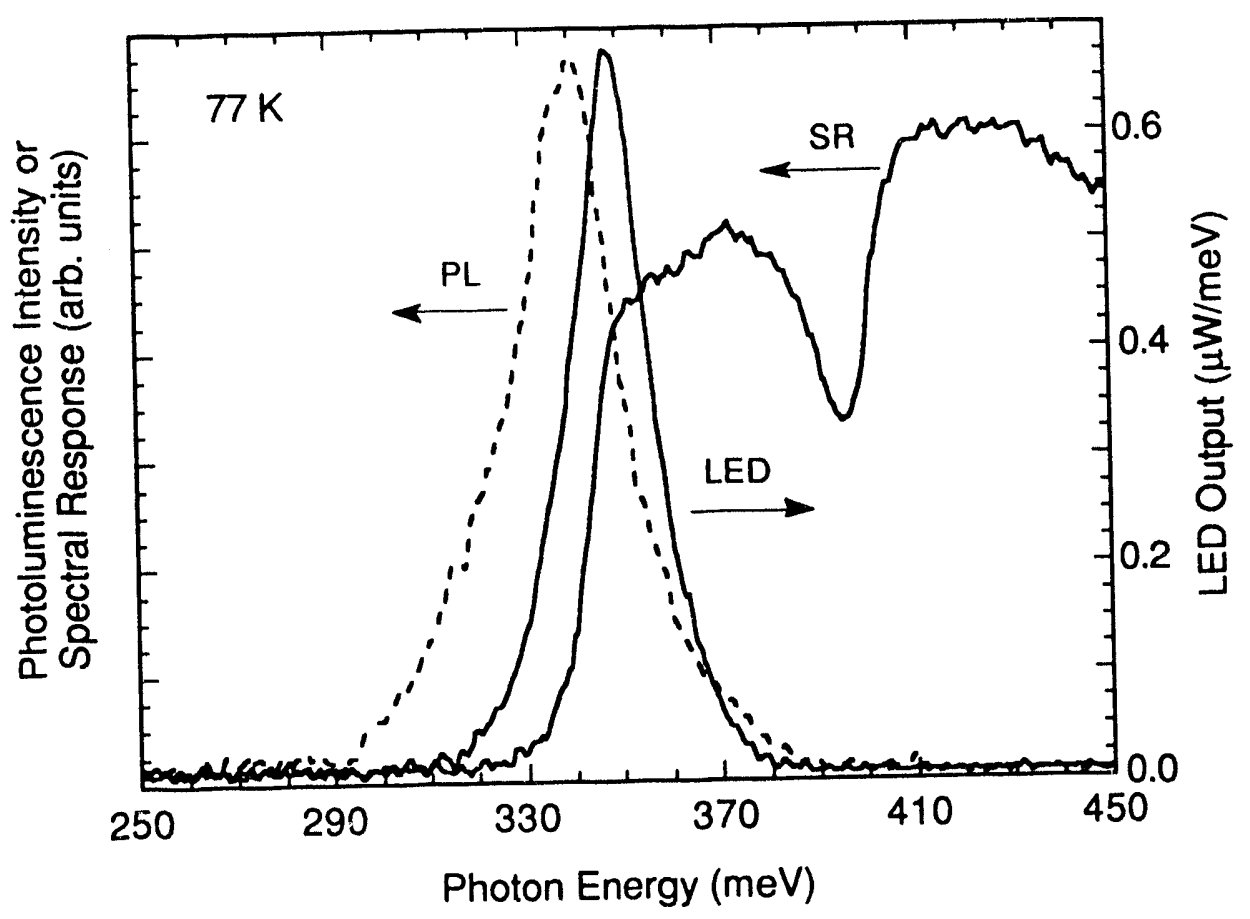

Figure 2. Forward-bias LED emission (LED), photoluminescence spectrum (PL), and photovoltaic spectral responsivity (SR) of the LED sample. All spectra were taken at $77 \mathrm{~K}$, and the injection current used for the LED emission measurement was $100 \mathrm{~mA}$.

Photoluminescence and LED emission were measured by operating the FTIR in a doublemodulation mode. The peak of the photoluminescence and the edge of the spectral response both occur at approximately the same energy, $340 \mathrm{meV}$. The LED emission occurs at slightly higher energy, with a peak of $348 \mathrm{meV}(3.56 \mu \mathrm{m})$ at high injection levels. With the shift of the LED emission to higher energy than the PL peak, we conclude that the band-filling increase in the emission energy dominates the injected carrier-induced decrease in the bandgap.

At $77 \mathrm{~K}$, the LED output power was approximately $0.02 \mathrm{~W} / \mathrm{cm}^{2}$ for a current density of $100 \mathrm{~A} / \mathrm{cm}^{2}$. This results in an efficiency of $0.06 \%$. The LED emission intensity falls-off rapidly above $100 \mathrm{~K}$, and we could not observe LED emission at $300 \mathrm{~K}$. Also, the LED I-V characteristic was soft, and the photoluminescence efficiency of the LED sample was less than that observed in our best SLSs. Overall, the LED emission efficiency and I-V characteristic of this initial SLS device were poor compared to that demonstrated for thick, LPE-grown InAsSbP LEDs emitting at $7 \mu \mathrm{m}$ and operating at $300 \mathrm{~K} .11,12$ There was significant residual lattice mismatch between the SLS and the substrate $(\Delta \mathrm{a} / \mathrm{a}=.0016)$ and we speculate that the emission efficiency and the I-V characteristic of the SLS device were degraded by dislocations forming as a result of this mismatch.

In conclusion, we have established the growth conditions for InAs $1-\mathrm{x} \mathrm{Sb}_{\mathrm{X}} / \mathrm{In}_{1-}$ yGayAs SLS's. The vapor-solid distribution coefficient for St can be described by a thermodynamic model. The PL peak energies of the SLS's and alloys grown under the conditions of this study are lower than those previously reported. The lower energy anomaly in these SLSs is probably due to ordering which is observed in InAs $s_{0.86} \mathrm{Sb}_{0.14}$. The first midwave infrared emitters that utilize SLSs with biaxially compressed InAsSb have been demonstrated. 
An SLS LED was constructed which emitted at $3.56 \mu \mathrm{m}$ with $0.06 \%$ efficiency at $77 \mathrm{~K}$. Demonstration of this device should allow us to construct electrically injected lasers. We anticipate that with improvements in material quality, we may soon demonstrate the reduction of Auger rates through higher temperature operation of midwave emitters with biaxially compressed In AsSb.

\section{ACKNOWLEDGMENTS}

This work was supported by the US DOE under Contract No. DE-AC04-94AL85000.

\section{REFERENCES}

[1] R. J. Menna, D. R. Capewell, R. U. Martinelli, P. K. York, and R. E. Enstrom, Appl. Phys. Lett. 59, (1991) 2127.

[2] R. M. Biefeld, J. Crystal Growth 75 (1986) 255.

[3] R. M. Biefeld, S. R. Kurtz, and S. A. Casalnuovo, J. Crystal Growth 124 (1992) 401.

[4] R. M. Biefeld, C. R. Hills and S. R. Lee, J. Crystal Growth 91 (1988) 515.

[5] S. R. Kurtz and R. M. Biefeld, Phys. Rev. B 44, 1143 (1991).

[6] R. M. Biefeld, J. Crystal Growth 75 (1986) 255.

[7] C. A. Larsen, S. H. Li, N. I. Buchan, and G. B. Stringfellow, J. Crystal Growth, 102 (1990) 126.

[8] Z. M. Fang, K. Y. Ma, D. H. Jaw, R. M. Cohen, and G. B. Stringfellow, J. Appl. Phys. 67, 7034 (1990).

[9] S. R. Kurtz, L. R. Dawson, R. M. Biefeld, D. M. Follstaedt, and B. L. Doyle, Phys. Rev. B 46, 1909 (1992).

[10] Su-Huai Wei and Alex Zunger, Appl. Phys. Lett. 58, 2684 (1991).

[11] N. P. Esina, N. V. Zotova, B. A. Matveev, N. M. Stus', G. N. Talalakin, and T. D. Abishev, Sov. Tech. Phys. Lett. 9, 167 (1983).

[12] A. Krier, Appl. Phys. Lett. 56, 2428 (1990). 

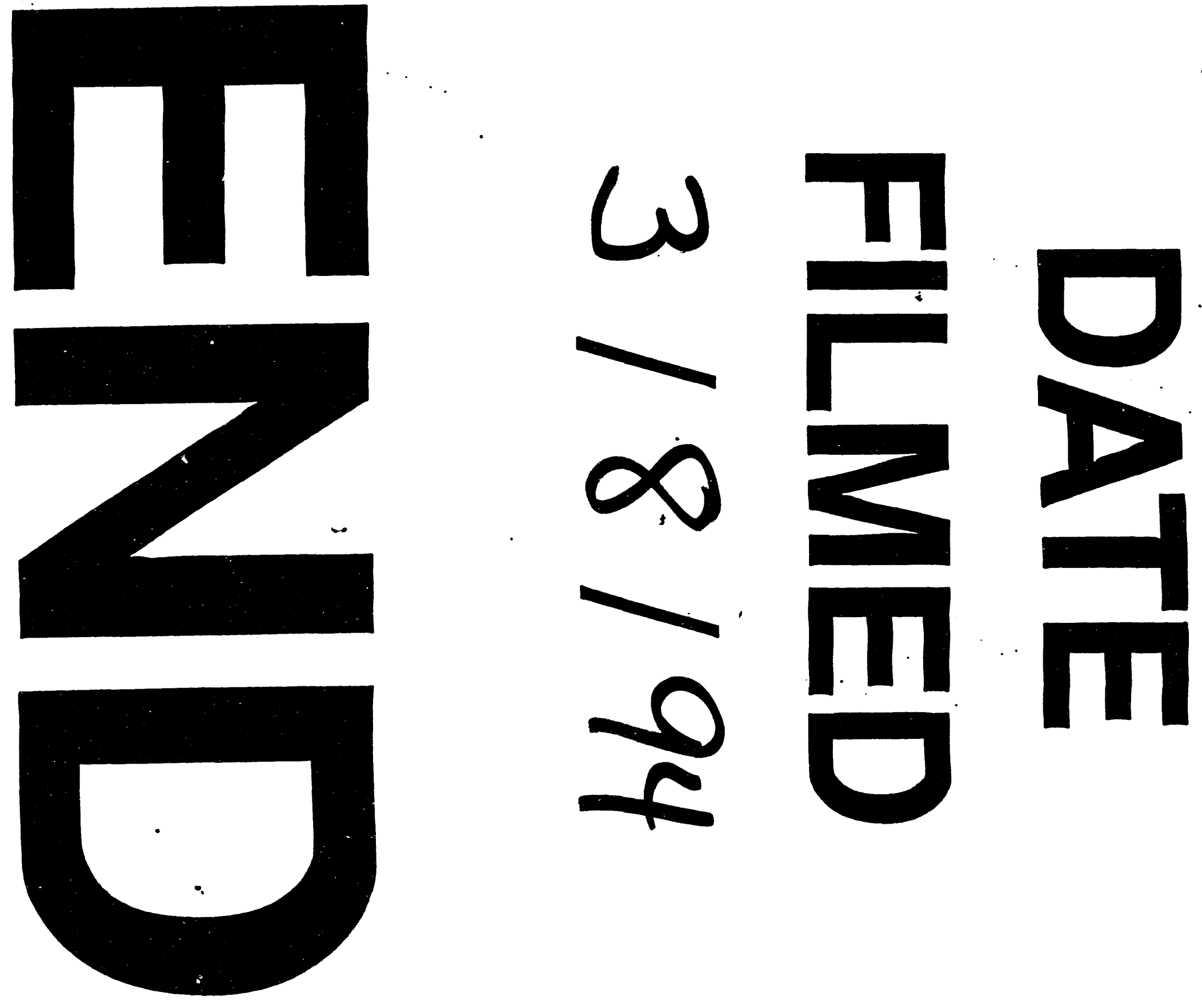
$$
\text { }
$$

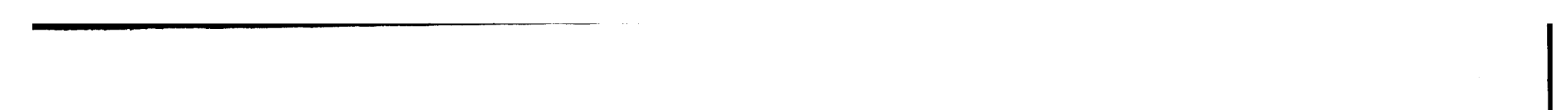

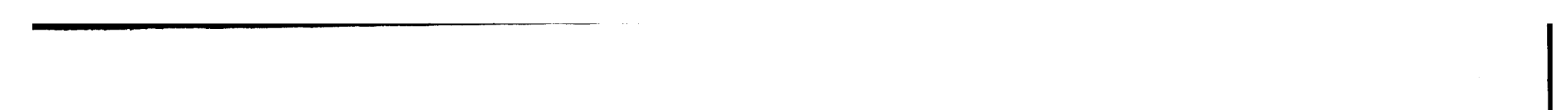

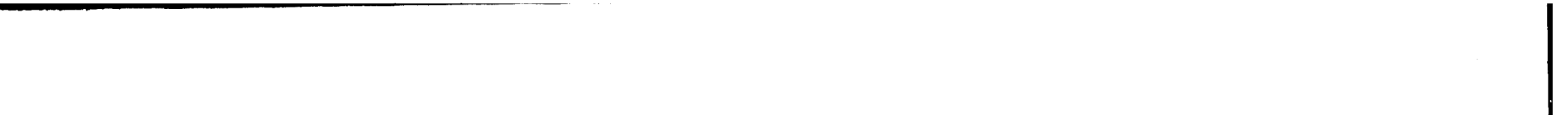

(1)

